\title{
Scanning Tunneling Microscopy of Electrochemically Activated Platinum Surfaces. A Direct Ex-Situ Determination of the Electrode Nanotopography
}

\author{
L. Vázquez, ${ }^{\dagger}$ J. Gómez ${ }^{\dagger}$ A. M. Barô,${ }^{*}{ }^{\dagger}$ N. García,${ }^{\dagger}$ M. L. Marcos,${ }^{\ddagger}$ J. González Velasco,${ }^{\ddagger}$ \\ J. M. Vara, ${ }^{\ddagger}$ A. J. Arvia, ${ }^{\ddagger}, \perp$ J. Presa, ${ }^{\S}$ A. Garcia, ${ }^{\S}$ and M. Aguilar ${ }^{\S, H}$ \\ Contribution from the Departamento de Fisica Fundamental, Universidad Autónoma de Madrid, \\ Departamento Electroquimica, Universidad Autōnoma de Madrid, and Centro de Investigaciōn \\ UAM-IBM, Cantoblanco 28049-Madrid, Spain. Received May 21, 1986
}

\begin{abstract}
A direct scanning tunneling microscopy ex-situ determination on the nanometer scale of the topography of electrochemically highly activated platinum electrodes is presented. A correlation between catalytic activity and surface microtopography becomes evident. This result gives support to a structural model for the activated electrode surface. In the model, a volume with a pebble-like structure allows electrocatalytic processes to occur practically free of diffusion relaxation contributions under usual voltammetric conditions.
\end{abstract}

Catalytic activity and surface roughness are of the outmost importance in heterogeneous catalysis, including electrocatalysis. The term roughness usually implies the existence of both macropores (macroroughness), which to a great extent are responsible for additional diffusional relaxation, ${ }^{1}$ and micropores (microroughness), which concern the effective catalytic area. ${ }^{2}$ Despite the close relationship between microroughness and catalytic activity, many real systems involve complex macro- and micropore structures which make the direct determination of microroughness a difficult task. A new approach to overcome this drawback is forseen by using metal surfaces which offer large catalytic activity, negligible micropore diffusional relaxation, and distribution of active sites very close to that of the starting material. ${ }^{3}$ This is the case, among others, with platinum electrodes in acid solutions, which have been subjected to a relatively fast square potential cycling, over a potential range such that a hydrous metal oxide multilayer is formed and immediately afterwards is electroreduced to yield a substantially increased active area. The new surface maintains the energy characteristics of the different processes, as can be seen in the corresponding electrochemical spectra for the hydrogen and oxygen adatom electroadsorption/electrodesorption. ${ }^{3}$ This type of electrode appears very suitable for having its surface structure charactcrized on a nanometric scale by means of the scanning tunneling microscope (STM). This instrument, which was recently developed, ${ }^{4,5}$ possesses simultaneously high horizontal and vertical resolution and furnishes three-dimensional, real space images of the surface of solid materials, by working either under vacuum or atmospheric pressure and at room temperature. ${ }^{6,7}$

The present work reports, for the first time, the microtopography of electrochemically activated platinum electrodes as determined by STM in air at atmospheric pressure and room temperature. These electrodes are of particular interest in electrocatalysis as platinum is employed, for instance, in fuel cell and water electrolysis technology. 2,8

\section{Results}

Voltammetric Data. In order to stress the difference between macro- and microroughness, we show the different electrochemical data of both surfaces. As an example of macroroughness we present the electrochemical spectra for the electroadsorption and electrodesorption of hydrogen and oxygen adatoms on platinized

\footnotetext{
* Address correspondence to this author.

† Departamento de Física Fundamental, Universidad Autōnoma de Madrid

¥Departamento Electroquímica, Universidad Autónoma de Madrid.

Centro de Investigación UAM-IBM.

$\perp$ Visiting Professor from INIFTA, Universidad Nacional de La Plata, Argentina.

"Present address: CSIC, Universidad Autōnoma Madrid (C-III), 28049Madrid, Spain.
}

platinum electrodes in acid solution (Figure 1a). The voltammogram even at a slow potential scan rate such as $0.2 \mathrm{~V} / \mathrm{s}$ is completely distorted as compared to that of bright polished platinum $^{1}$ (Figure $1 \mathrm{~b}$ ). On the other hand, platinum electrodes resulting from the repetitive square wave potential treatments (RSWPS), as described in the Experimental Section, maintain the energy characteristics of the different processes, and in addition exhibit a substantial increase in the voltammetric charge for the different electrochemical reactions occurring within the potential range of thermodynamic stability of bulk water. ${ }^{3}$

The degree of activation of the new electrode surface can be followed through the ratio of the voltammetric charge at $0.2 \mathrm{~V} / \mathrm{s}$, both before and after the RSWPS treatment, to either the hydrogen or oxygen adatom monolayer electroadsorption/electrodesorption processes (Figure 1). In addition to the increase in voltammetric charge, the new electrode surface also shows a significant change in the distribution of current peaks which was assigned to a change in the contribution of the different crystallographic planes of platinum, ${ }^{9-15}$ as confirmed by $\mathrm{x}$-ray diffractometry. ${ }^{3}$ This can be immediately seen in Figure $1 \mathrm{~b}$ where the ratio of weakly to strongly adsorbed hydrogen adatom elec-

(1) Luna, A. C.; Kessler, T.; Triaca W. E.; Arvia, A. J. J. Appl. Electrochem., in press.

(2) Bockris, J. O'M.; Srinivasan, S. Fuel Cells: Their Electrochemistry; McGraw-Hill: New York, 1969; Chapter 5, p 230.

(3) Chialvo, A. C.; Triaca, W. E.; Arvia, A. J. J. Electroanal. Chem. 1983, 146,$93 ; 1984,171,303$.

(4) Binnig, G.; Rohrer, H. Helv. Phys. Lett. 1982, 55, 726; Surf. Sci. 1983, 126,236 .

(5) Binnig, G.; Rohrer, H.; Gerber, Ch.; Weibel, E. Appl. Phys. Lett. 1982, 40 178; Phys. Rev. Lett. 1983, 50, 120.

(6) Lozane, A. L.; Elrod, S. A.; Quate, C. F. Phys. Rev. Lett. 1985, 54 , 2433; Ringer, M.; Hidber, H. R.; Schlogl, R.; Oelhafen, P.; Güntherodt, H. J. Appl. Phys. Lett. 1985, 46, 832 .

(7) Baró, A. M.: Miranda, R.; Alamån, J. Garcia, N.; Binnig, G.; Rohrer, H.; Gerber, Ch.; Carrascosa, J. L. Nature (London) 1985, 315, 253; Garcia, N.; Barô, A. M.; Miranda, R.; Rohrer, H.; Gerber, Ch.; Garcia-Cantú, R.; Peña, J. L. Metrología 1985, $21,566$.

(8) Tilak, B. V.; Lu, P. W. T.; Coleman, J. E. Srinivasan, S. In Comprehensive Treatise of Electrochemistry; Bockris, J. O'M.; Conway, B. E.; Yeager, E.; White, R. E., Eds; Plenum Press: New York, 1981; Vol. 2, pp $1-104$.

(9) Ross, P. N., Jr. J. Electroanal. Chem. 1977, 76, 139

(10) Hubbard, A T.; Ishikawa, R. M.; Katekaru, J. J. Electroanal. Chem. $1978,86,289$

(11) Yeager, E.; O'Grady, W. E.; Woo, M. J. C.; Hagans, P. J. Electrochem. Soc. 1978, 125, 125 .

(12) Yamamoto, K.; Kolb, D. M.; Kotz, R.; Lehmpful, G. J. Electroanal. Chem. 1979, 96, 233.

(13) Aberdam, D.; Corotte, C.; Dufayard, D.; Durand, R.; Faure, R.; Guinet, G. Proc. 4th Int. Conf. Solid Surf. 1980, 1, 622 (Supplement to Le Vide, Les Couches Minces No. 201 1980

(14) Wagner, F. T.; Ross, P. N., Jr. J. Electroanal. Chem. 1983, 150, 141

(15) Cerviño, R. M.; Triaca, W. E.; Arvia, A. J. J. Electroanal. Chem $1985,182,51$. 


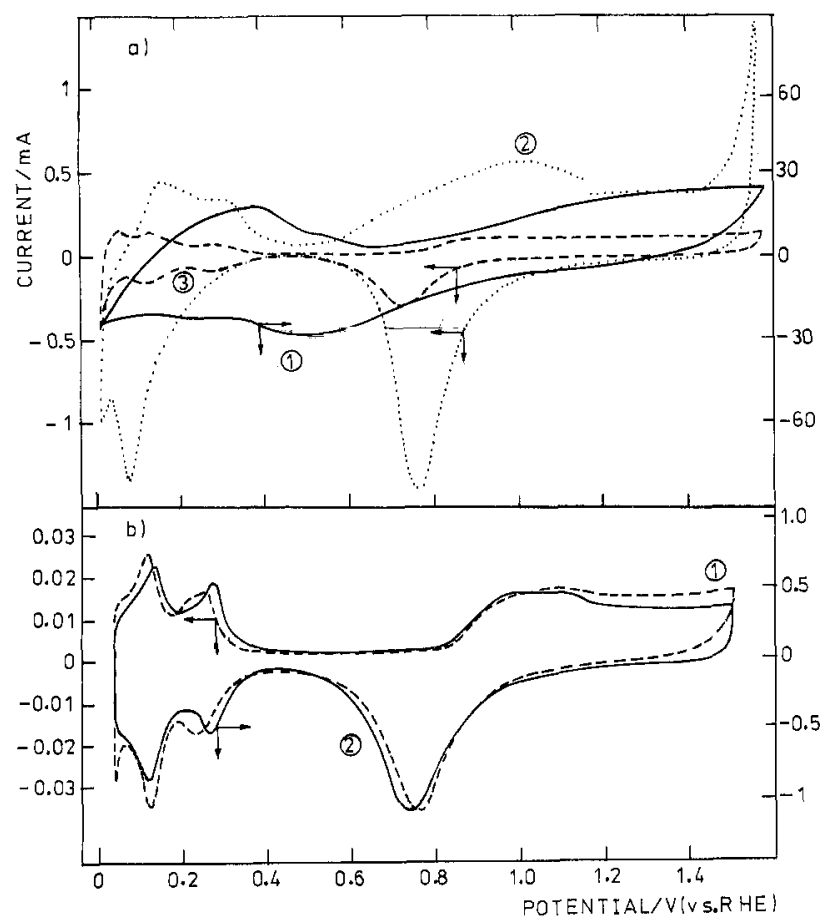

Figure 1. Electrochemical spectra resulting from the application of a repetitive triangular potential scan taken at a rate $v$ with different electrodes in acid solutions, at $25^{\circ} \mathrm{C}$. a: (1) Platinized platinum (400X activation) in $1 \mathrm{M} \mathrm{HClO}_{4}, v=0.2 \mathrm{~V} / \mathrm{s}$ (full trace); (2) platinized platinum (400× activation) in $1 \mathrm{M} \mathrm{HClO}_{4}, v=0.002 \mathrm{~V} / \mathrm{s}$ (dotted trace); (3) bright pc platinum (blank) in $1 \mathrm{M} \mathrm{HClO}_{4}, v=0.2 \mathrm{~V} / \mathrm{s}$ (dashed trace). Note the large increase in charge for voltammograms 1 and 2 as compared to 3 , and the different behavior at 0.2 and $0.002 \mathrm{~V} / \mathrm{s}$, for the same electrode. The voltammogram of platinized platinum is influenced by diffusional relaxation at pores. b: (1) Bright pc platinum (blank) in $0.5 \mathrm{M} \mathrm{H}_{2} \mathrm{SO}_{4}, v=0.2 \mathrm{~V} / \mathrm{s} \mathrm{(full} \mathrm{trace);} \mathrm{(2)} \mathrm{electrochemically}$ activated pc platinum ( $30 \times$ activation) in $0.5 \mathrm{M} \mathrm{H}_{2} \mathrm{SO}_{4}, v=0.2 \mathrm{~V} / \mathrm{s}$ (dashed trace). The change in the relative height of hydrogen adatom electroadsorption and electrodesorption current peaks as compared to the blank should be noticed. This is an indication that some preferred crystallographic orientation of grains at pc platinum has been produced by the electrochemical treatment.

trodesorption peaks, at $\approx 0.15$ and $\approx 0.25 \mathrm{~V}$, respectively, is enhanced. This is expected for the development of a (100)-type preferred oriented platinum surface, and it has also been observed by STM. ${ }^{16}$ Potentials are referred to the reversible hydrogen electrodes in the same electrolyte solution.

STM Imaging. STM patterns of untreated and treated specimens were obtained. The untreated specimens refer to either the metal surface (plate) as received (virgin specimen) or after it had been melted, quenched in water, and cleaned in acid (beadshaped), or after it had been subjected to several repetitive triangular potential scans at $0.2 \mathrm{~V} / \mathrm{s}$ in the 0 - to $1.5-\mathrm{V}$ range (blank specimen). Occasionally, for a straightforward comparison of results and to avoid any peculiarity due to the independent treatment of the specimens, one portion of the same surface was left blank and the rest of it was subjected to the RSWPS treatment. It should be noticed that the voltammetric responses of the different specimens before and after the STM measurements were the same.

The STM patterns of the blank become independent of the thermal treatment (at the nanometer scale range) and shape and size of the specimen, as checked for plate and bead-shaped platinum electrodes. The first thing one observes is that the surface of the blank (Figure 2a) is much smoother than that of the virgin specimen, which means that the voltammetric cycling at $0.2 \mathrm{~V} / \mathrm{s}$ has already caused smoothing of the surface after about 100 potential scans between 0 and $1.5 \mathrm{~V}$.

(16) Gỏmez, J.; Vãzquez, L.; Barō, A. M.; Garcia, N.; Perdriel, C. L.; Triaca, W. E.; Arvia, A. J. Nature (London) 1986, 323, 612
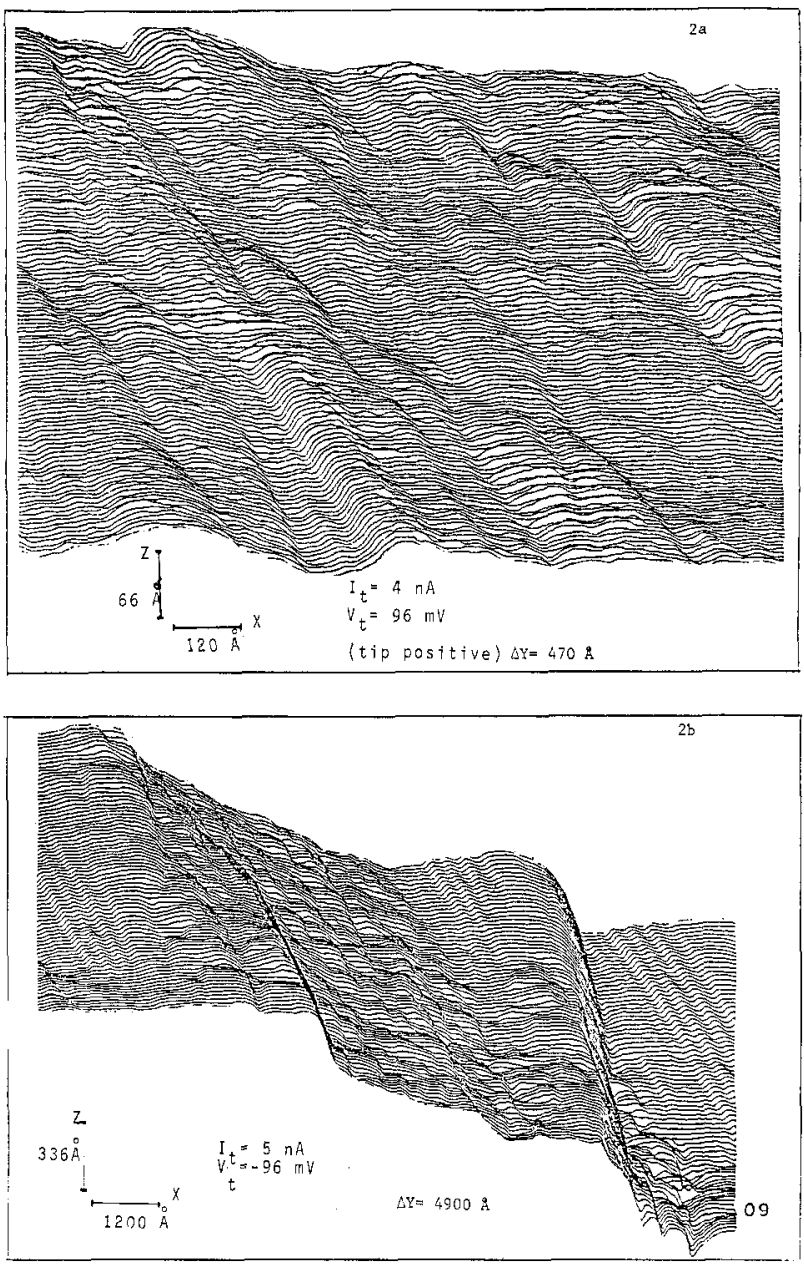

Figure 2. STM patterns: (a) blank pe platinum electrode surface (the smooth surface exhibits a corrugation of $\approx 50 \AA$ ); (b) treated platinum electrode surface ( $40 \times$ activation). Three different morphologies are distinguished, namely, dome-like (central region), parallel-ridge (various regions), and deep corrugated structures (lower right region). $\Delta Y$ means the total length scanned by the slow $Y$ piezo.

Platinum specimens were subjected to RSWPS treatments to yield 40-, 60-, and 100-fold increases in voltammetric area. STM patterns of these specimens were then obtained by scanning different surface regions under various magnifications. The treated platinum surfaces exhibit a nonhomogeneous topography; an illustrative picture of this is presented in Figure $2 \mathrm{~b}$. The inhomogeneity phenomenon is presumably related to different domains in the hydrous platinum oxide layer structure resulting during the RSWPS treatment which reflects the polycrystalline characteristics of the starting material. The nonhomogeneous topography of treated platinum is characterized by the following three main morphologies.

(1) A relatively high-density structure (Figure 3a,b) which appears either as high or low domes localized in certain regions which are randomly distributed over the surface (Figure $3 \mathrm{c}$ ). This structure is described here as a pebble-like structure. The transition from low to high dome structures occurs rather abruptly (Figure 3c). For a $40 \times$ increase in voltammetric charge the average radius of the domes is $\approx 100 \AA$ (Figure $3 a$ ). The top of each dome is relatively flat with corrugations no more than $1 \AA$ high (Figure 3a). The prevalence of this morphology suggests that the structure of activated platinum electrodes results from the piling up of small nearly "rounded" platinum crystallites produced through the slow electroreduction of the hydrous oxide layer grown under the RSWPS treatment.

Recently we have incorporated an IBM PC computer for data acquisition and image processing. We have taken 256 scans of the region shown in Figure 3a. The data analysis and processing are given in Figure 4a,b. The structure clearly shows channels 

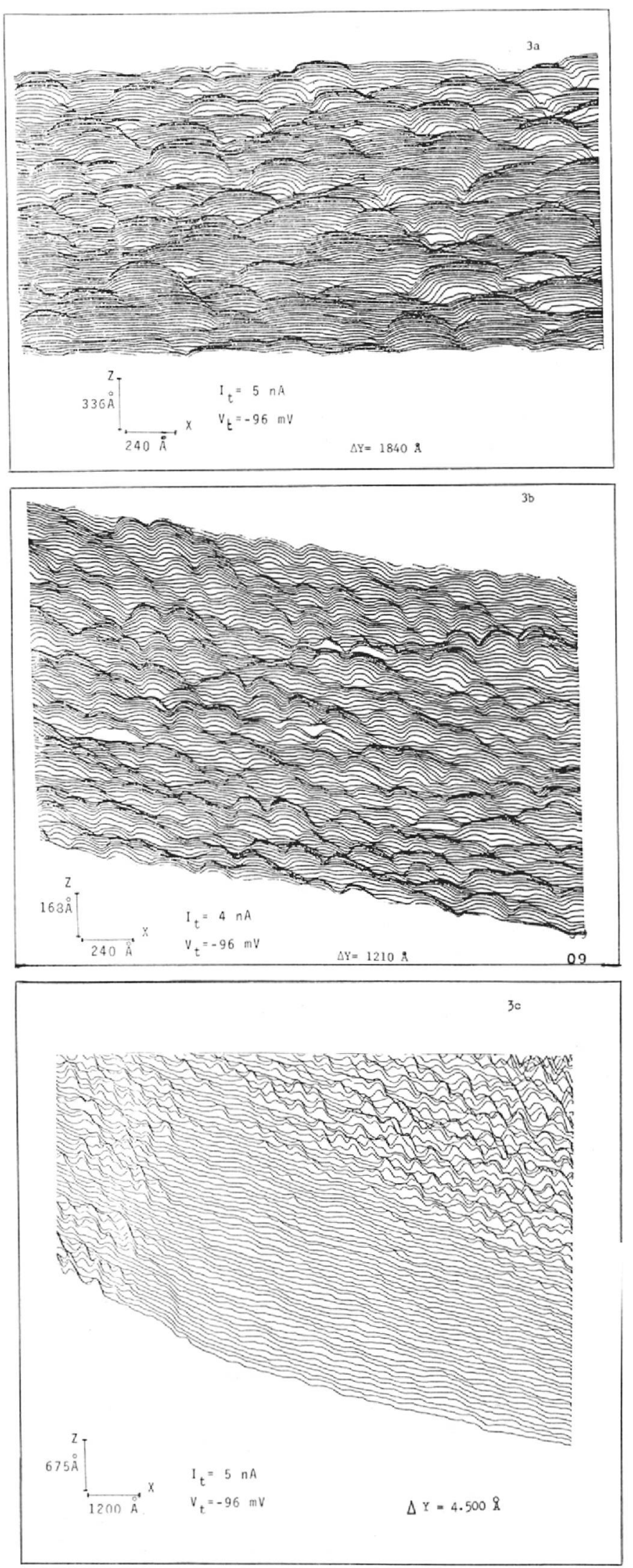

Figure 3. Details of the dome-like structure for treated platinum electrode surfaces: (a) $40 \times$ activation, (b and c) $60 \times$ activation.

(white regions in Figure $4 \mathrm{~b}$ ) surrounding the different domes. We believe that this randomly piled pebble-like structure penetrates into the bulk of electroreduced platinum, and is responsible for the increase in catalytic activity as discussed later.

(2) Flat regions with parallel ridge-like structures (Figure 2b), which resemble the structures previously observed in the metal surface electrorecrystallization associated with the development

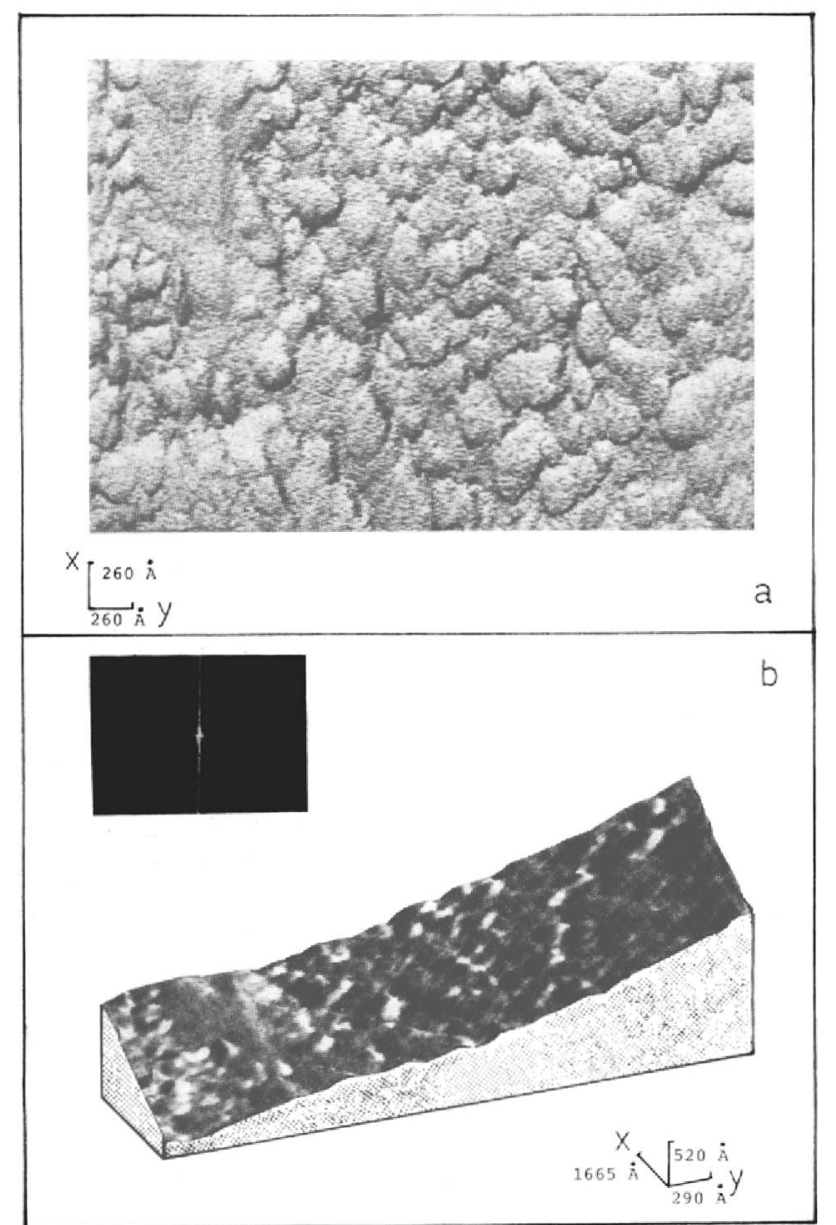

Figure 4. Processed image from STM patterns depicted in Figure 3 with the $Y$ axes lying in the horizontal position. The right-side portion of this figure corresponds to Figure 3a. The number of scans in this figure is larger than in Figure 3: (a) top view at $10^{\circ}$ elevation, the same magnification for the three axis; (b) space view. Insert: fourier transform of data showing that there is neither a significant noise nor any periodic structure.

of (100)-type preferred oriented platinum. ${ }^{16}$. For a $40 \times$ increase in voltammetric charge the distances between adjacent ridges and their average height are about 330 and $40 \AA$, respectively (Figure $2 b)$.

(3) Localized surface regions with large and deep corrugations (Figure 2b). The density of this structure substantially increases according to the duration of the RSWPS.

In conclusion, the STM patterns furnish for the first time direct information about the microtopography of active platinum electrodes measured ex situ on the nanometer scale. They also indicate a correlation between the activation of the electrode and the change in surface topography.

\section{Discussion}

In order to explain the surprisingly large and electrochemically monitorable increase in activity of treated platinum electrodes, we have to think of an increase in the number of reacting sites without a significant change in energy distribution. The increase in the number of reacting sites can be achieved in three different ways, namely, by increasing the surface roughness, by promoting close-packed crystallographic structures, and by creating a volume structure which is equally accessible to reactants. According to our data neither the first nor the second possibility by themselves explains the large increase in activity of the treated specimens. The contribution of roughness, as numerically calculated from the data-processed STM patterns depicted in Figure 4, only accounts for an area increase factor of about 1.07 for the specimen involving $40 \times$ activation. The figure 1.07 is obtained by comparing the above-mentioned calculated area with that of a perfect plane. It is worth remarking that this figure does not substantially in- 
crease with other surface geometries. For example, if we take spherically shaped domes and arrange them in the most compact way, the area increase factor is 1.7. Likewise, the development of (100)-type preferred oriented platinum, even under $100 \%$ efficiency, would contribute less than $20 \%$ real area increase. Therefore, the development of the catalytic activity in the volume of the electroreduced platinum crystallites must play the most important role, as may be concluded from the surface microtopography.

On the basis of these results, the behavior of activated platinum electrodes can be explained by admitting that each pebble-like crystallite can be represented by a sphere of $100 \AA$ average radius. The sphere ensemble is made by piling up the spheres in a volume defined by the geometric electrode area times the average thickness of the electroreduced platinum layer. This thickness can be obtained from the corresponding oxide electroreduction charge; its value for a 100 times activation can be estimated as $5 \times 10^{3}$ $\AA$. This volume structure should be wetted by the electrolyte solution, making the entire surface of each sphere equally accessible to reactants through interconnected inner channels. The number of spheres of $100 \AA$ radius per $\mathrm{cm}^{2}$ which can be accomodated within the volume of the active electrode is about $10^{12}$. Therefore, provided that the entire surface of each sphere is catalytically active, the large activation factor, of the order of $10^{2}$, deduced from the voltammetric charge at $0.2 \mathrm{~V} / \mathrm{s}$ can be immediately understood.

For an average thickness of about $10^{3} \AA$ and diffusion coefficients of the order of $10^{-6} \mathrm{~cm}^{2} / \mathrm{s}$ as expected for most ions in aqueous solutions, it is obvious that, even at the rate of $1 \mathrm{~V} / \mathrm{s}$, the contribution of diffusional relaxation should become negligible. Hence, under usual voltammetric conditions, this type of platinum electrodes, in contrast to conventional platinized platinum (Figure 1a), should offer practically no anomalous voltammetric response (Figure 1b).

The proposed simple model explains the important fact that the electrocatalytic activation remains practically the same for electrochemical processes occurring in different potential ranges with reactants and intermediates of different sizes, as is the case for hydrogen and oxygen adatom electroadsorption/electrodesorption, ${ }^{3}$ adsorbed ethylene electroxidation, ${ }^{17}$ and reduced carbon dioxide electroxidation. ${ }^{18}$

\section{Experimental Section}

Preparation of the Platinum Electrodes. The preparation of the activated platinum electrode surfaces was made by following the technique already described in the literature ${ }^{3}$ It consisted of a repetitive square wave potential signal (RSWPS) at $2.5 \mathrm{kHz}$ between 0 and $2.3 \mathrm{~V}$ applied for a certain time to polycrystalline $(\mathrm{pc}$ ) platinum electrodes (geometric area ranging from 0.1 to $2 \mathrm{~cm}^{2}$ ). The electrodes from Specpure quality Johnson Matthey Chemical Ltd. and Engelhard $99.99 \%$ purity were immersed in either $1 \mathrm{M} \mathrm{HClO}_{4}$ or $0.5 \mathrm{M} \mathrm{H}_{2} \mathrm{SO}_{4}$, at $25^{\circ} \mathrm{C}$. During the RSWPS treatment a relatively thick hydrous platinum oxide layer was formed, whose thickness depended on the duration of RSWPS. Immediately afterwards the hydrous oxide multilayer was electroreduced at $0.01 \mathrm{~V} / \mathrm{s}$, yielding the new platinum surface.

Evaluation of Platinum Electrode Roughness. The initial true electrode area was determined through the hydrogen adatom monolayer charge resulting from conventional voltammograms run with triangular potential sweeps at $0.2 \mathrm{~V} / \mathrm{s}$ between 0.01 and $1.40 \mathrm{~V}$ in $0.5 \mathrm{M} \mathrm{H}_{2} \mathrm{SO}_{4}$ at $25^{\circ} \mathrm{C}$. The average hydrogen adatom monolayer charge was taken as 210 $\mu \mathrm{C} / \mathrm{cm}^{2} .^{9}-12$ The relative increase in the electrode real surface area was evaluated as the ratio between the hydrogen electroadsorption monolayer charge before and after the RSWPS treatment.

STM Measurements. STM data were taken at a tunneling voltage of $-10 \mathrm{mV}$ (tip negative) and a tunneling current of $5 \mathrm{nA}$. A typical scanning frequency was $0.1 \mathrm{~Hz}$. Vertical sensitivity was in the subnanometer range whereas lateral sensitivity was kept in the nanometer range.

Acknowledgment. We acknowledge discussions with J. M. Soler and J. J. Saenz. We also appreciate the very useful help with the electronic equipment from J. Pedrosa.

Registry No. Pt, 7440-06-4; $\mathrm{HClO}_{4}, 7601-90-3 ; \mathrm{H}_{2} \mathrm{SO}_{4}, 7664-93-9 ; \mathrm{H}_{2}$ 1333-74-0.

(17) Piovano, E. M.; Chialvo, A. C.; Triaca, W. E.; Arvia, A. J. J. Appl. Electrochem., in press. tion.

(18) Marcos, M. L.; Velasco, J. G.; Vara, J. M.; Arvia, A. J. in prepara-

\title{
Bonding Capabilities of Nickel Cluster Ions: Synthetic Chemistry in a Molecular Beam
}

\author{
Pierre Fayet, ${ }^{* \dagger}$ Michael J. McGlinchey, ${ }^{* \ddagger}$ and Ludger H. Wöste ${ }^{* \dagger}$ \\ Contribution from the Institut de Physique Expérimentale, Ecole Polytechnique Fédërale de \\ Lausanne, CH-1015 Lausanne, Switzerland, and Department of Chemistry, McMaster University, \\ Hamilton, Ontario, Canada L8S4M1. Received August 6, 1986
}

\begin{abstract}
Nickel cluster ions, size-selected by quadrupole mass spectrometry, were treated with carbon monoxide to yield in the gas phase nickel-carbonyl complexes of the type $\left.\mathrm{Ni}_{n}(\mathrm{CO})\right)_{k}{ }^{+}$and $\mathrm{Ni}_{n} \mathrm{C}(\mathrm{CO})_{l}^{+}$where $n$ ranges from 1 through 13 and $k$ and $l$ vary as a function of the cluster size $n$. The stoichiometry of these clusters correlates extremely well with the electron-counting rules proposed by Lauher.
\end{abstract}

\section{Introduction}

Over the past 15 years, detailed spectroscopic investigations of matrix isolated atoms and small clusters have provided much insight into catalytic processes occurring on metal surfaces.' Nevertheless, it is still extremely difficult to build up a concentration of a single chemical species although some progress has been made by cryophotoclustering techniques. ${ }^{2}$ There are obvious attractions to working in the gas phase since one can avoid the complications arising from solvents or from matrix effects. ${ }^{3}$

\footnotetext{
${ }^{\dagger}$ Institut de Physique Expérimentale.

${ }^{\ddagger}$ McMaster University.
}

Molecular beam expansion combined with mass spectrometry is a well-established technique to investigate optical and chemical properties of metal clusters in the gas phase. Experiments,

(1) (a) Moskovits, M; Ozin G. A. In Cryochemistry; Wiley-Interscience New York, 1976. (b) Burdett, J. K. Coord. Chem. Rev. 1978, 27, 1. (c) Ozin, G. A. Ibid. 1979, 28, 117 . 79

(2) Power, W. J.; Ozin, G. A. Adv. Inorg. Chem. Radiochem. 1980, 23,

(3) (a) Geusic, M. E.; Morse, M. D.; Smalley, R. E. J. Chem. Phys. 1986, 82, 590. (b) Trevor, D. J.; Whetten, R. L.; Cox, D. M.; Kaldor, A. J. Am. Chem. Soc. 1985, 107, 518. (c) Richtmeier, S. C.; Parks, E. K.; Liu, K.; Pobo,

L. G.; Riley, S. J. J. Chem. Phys, 1985, 82, 3659. 